\title{
Hepatocyte growth factor improves bone regeneration via the bone morphogenetic protein-2-mediated NF-kB signaling pathway
}

\author{
RUIXIN ZHEN, JIANING YANG, YU WANG, YUBO LI, BIN CHEN, YOUXIN SONG, GUIYUN MA and BO YANG
}

Department of Spinal Surgery, Chengde Medical College Affiliated Hospital, Chengde, Hebei 067000, P.R. China

Received September 27, 2016; Accepted November 3, 2017

DOI: $10.3892 / \mathrm{mmr} .2018 .8559$

\begin{abstract}
Bone regeneration is an important process associated with the treatment of osteonecrosis, which is caused by various factors. Hepatocyte growth factor (HGF) is an active biological factor that has multifunctional roles in cell biology, life sciences and clinical medicine. It has previously been suggested that bone morphogenetic protein (BMP)-2 exerts beneficial roles in bone formation, repair and angiogenesis in the femoral head. The present study aimed to investigate the benefits and molecular mechanisms of HGF in bone regeneration. The viability of osteoblasts and osteoclasts were studied in vitro. In addition, the expression levels of tumor necrosis factor (TNF)- $\alpha$, monocyte chemotactic protein (MCP)-1, interleukin (IL)-1 and IL- 6 were detected in a mouse fracture model following treatment with HGF. The expression and activity of nuclear factor (NF)- $\mathrm{kB}$ were also analyzed in osteocytes post-treatment with HGF. Histological analysis was used to determine the therapeutic effects of HGF on mice with fractures. The migration and differentiation of osteoblasts and osteoclasts were investigated in HGF-incubated cells. Furthermore, angiogenesis and BMP-2 expression were analyzed in the mouse fracture model post-treatment with HGF. The results indicated that HGF regulates the cell viability of osteoblasts and osteoclasts, and also balanced the ratio between osteoblasts and osteoclasts. In addition, HGF decreased the serum expression levels of TNF- $\alpha$, MCP-1, IL-1 and IL-6 in experimental mice. The results of a mechanistic analysis demonstrated that HGF upregulated $\mathrm{p} 65$, I $\kappa \mathrm{B}$ kinase $-\beta$ and I $\mathrm{B} \alpha$ expression in osteoblasts from experimental mice. In addition, the expression levels of vascular endothelial growth factor, BMP-2 receptor, receptor activator of NF- $\mathrm{KB}$ ligand and macrophage colony-stimulating factor were upregulated by HGF, which may effectively promote blood vessel regeneration, and contribute to the formation and
\end{abstract}

Correspondence to: Professor Ruixin Zhen, Department of Spinal Surgery, Chengde Medical College Affiliated Hospital, 36 Nanyingzi Street, Chengde, Hebei 067000, P.R. China

Email: zhenruixindr@yeah.net

Key words: hepatocyte growth factor, bone morphogenetic protein-2, angiogenesis, fracture, bone regeneration, nuclear factor- $\kappa \mathrm{B}$ revascularization of tissue-engineered bone. Furthermore, HGF promoted BMP-2 expression and enhanced angiogenesis at the fracture location. These results suggested that HGF treatment may significantly promote bone regeneration in a mouse fracture model. In conclusion, these results indicated that HGF is involved in bone regeneration, angiogenesis and the balance between osteoblasts and osteoclasts, thus suggesting that HGF may be considered a potential agent for the treatment of fractures via the promotion of bone regeneration through regulation of the BMP-2-mediated NF- $\mathrm{kB}$ signaling pathway.

\section{Introduction}

Bone regeneration is a biochemical process, which is required in response to the progression of cartilage wear and tear, damage and deformation caused by various types of joint disease (1). Previous studies have investigated the abilities of various proteins and cells to decrease inflammation associated with bone marrow, bone regeneration, vessel walls, adipose tissue, muscle, periosteum, tendons, peripheral circulation, umbilical cord blood, skin and dental tissues (2-4). In recent years, research has focused on the molecular mechanisms underlying bone regeneration and fracture repair $(5,6)$. In addition, extracellular signaling molecules, including platelet-derived growth factor, fibroblast growth factor (FGF) and vascular endothelial growth factor (VEGF) have been reported to promote fracture healing and bone regeneration (7). Furthermore, bone-healing processes, including vascularization, inflammatory inhibition and mesenchymal cell entry to the fracture site, have been reported to be mediated by extracellular signaling molecules (8). These findings indicate that targeted bone production and regeneration may contribute to the reduction of convalescence following treatment of fractures $(1,9)$. The present study investigated the role of the extracellular signaling molecule hepatocyte growth factor (HGF) in inflammation, osteoblast and osteoclast balance, bone production and bone regeneration in a mouse fracture model. In addition, bone morphogenetic protein (BMP)-2 production and alterations in the nuclear factor (NF)- $\mathrm{kB}$ signaling pathway were detected in the mouse model.

HGF is produced by mesenchymal cells during organ injury and serves a crucial role in the process of bone regeneration (10). HGF is an active biological factor that exerts multifunctional effects on osteogenesis, and also serves a critical role in kidney development, acute injury and regeneration; HGF is activated 
by proteolytic cleavage at the site of injury resulting in formation of the biologically active HGF protein (11). A previous study reported that levels of HGF in the serum were correlated with quality of life in patients undergoing hemodialysis (12). In addition, biologically active HGF can suppress fibrosis; the molecular basis for HGF-mediated regression of renal fibrosis was elaborated in a previous report $(13,14)$. Therefore, it was hypothesized that HGF may be regarded as a local acute phase protein that is beneficial for bone regeneration in various bone diseases. The results of the present study suggested that HGF promoted bone regeneration via regulation of BMP-2 expression in osteocytes in vitro and in vivo.

BMPs are members of the transforming growth factor- $\beta$ superfamily, which regulate numerous cellular activities in bone regeneration (15). A previous study on BMP-2-releasing gelatin/ $\beta$-tricalcium phosphate sponges revealed that BMP-2 may be considered a potential protein for the induction of bone regeneration in segmental bone defects (16). In addition, it has been reported that BMP-2 serves an important role in various forms of arthritis and disease activity. Grcevic et al (17) indicated that peripheral blood expression profiles of BMPs may be used as markers for arthritis, disease activity, therapeutic responsiveness and prognosis. Lories and Luyten also suggested that BMPs are beneficial for the repair of joint destruction and tissue responses that determine the outcome of chronic arthritis (18). Furthermore, BMP-2 is a member of the BMP family, which has been reported to possess high potential for bone formation, inflammatory inhibition in joints and synovial repair $(19,20)$. In the present study, the in vivo effects and molecular mechanisms of BMP-2 were investigated in a mouse fracture model. Inflammation was also analyzed.

The present study aimed to investigate the association between bone tissue regeneration and inflammation in a mouse model of fracture. The results indicated that HGF treatment markedly promoted bone tissue regeneration and inhibited the expression of inflammatory factors. Notably, the present study demonstrated that HGF improves bone tissue regeneration via the BMP-2-mediated nuclear factor $(\mathrm{NF})-\kappa \mathrm{B}$ signaling pathway, thus suggesting that HGF may be considered a promising agent for the treatment of patients with fractures.

\section{Materials and methods}

Ethics statement. The present study was conducted in strict accordance with the recommendations in the Guide for the Care and Use of Laboratory Animals at Chengde Medical College Affiliated Hospital (Chengde, China). The study was approved by the ethics committee of Chengde Medical College Affiliated Hospital. All surgeries and euthanasia were performed under intravenous sodium pentobarbital anesthesia (37 mg/kg).

Animal study. A total of 20 male C57BL/6J mice (6-8 weeks, 28-35 g) were purchased from Shanghai SLAC Laboratory Animal Co., Ltd. (Shanghai, China). All animals were housed in a temperature-controlled facility at $23 \pm 1^{\circ} \mathrm{C}$ with a relative humidity of $50 \pm 5 \%$, a $12 \mathrm{~h}$ light/dark cycle and unlimited access to food and water. Mice were subjected to an artificial fracture in the right paw as described previously (21). The mice were divided into two groups and were maintained under a normal schedule with free access to standard diet and water. On day 2 after model establishment, mice received treatment with HGF (10 mg/kg; Sigma Aldrich; Merck KGaA, Darmstadt, Germany) or the same volume of PBS (control) by intravenous injection. The body weights of the experimental mice were measured prior to each injection. Each mouse received 15 daily treatments. All mice were sacrificed on day 30 for histological analysis. Osteoblasts and osteoclasts were obtained from experimental mice and then isolated from one another as described previously $(22,23)$ on day 30 .

Cell culture. Osteocytes were obtained from mice with fractures prior to treatment as described previously $(22,23)$ and then cultured in minimum essential media (MEM, Sigma-Aldrich; Merck KGaA) and supplemented with $10 \%$ fetal bovine serum (Sigma-Aldrich; Merck KGaA). Osteocytes were then treated with $\mathrm{HGF}(2 \mathrm{mg} / \mathrm{ml})$ and cultured in a humidified incubator containing $5 \% \mathrm{CO}_{2}$ for $24 \mathrm{~h}$ at $37^{\circ} \mathrm{C}$.

MTT assay. Osteoblasts and osteoclasts were separately cultured in Dulbecco's Modified Eagle's medium (DMEM; Gibco; Thermo Fisher Scientific, Inc.) and supplemented with $10 \%$ fetal bovine serum (FBS; Gibco; Thermo Fisher Scientific, Inc.) for $24 \mathrm{~h}$ at $37^{\circ} \mathrm{C}$. Osteoblasts and osteoclasts were then incubated with $\mathrm{HGF}(2 \mathrm{mg} / \mathrm{ml})$ in a 96-well plate for $24 \mathrm{~h}$ at $37^{\circ} \mathrm{C}$. A total of $20 \mu \mathrm{MTT}(5 \mathrm{mg} / \mathrm{ml})$ in PBS solution was added to each well and cells were then incubated for a further $4 \mathrm{~h}$ at $37^{\circ} \mathrm{C}$. Medium was then removed and $100 \mu \mathrm{l}$ dimethyl sulfoxide was added to dissolve the formazan crystals. The viability of the cells was then determined using an ELISA reader (Bio-Rad Laboratories, Inc., Hercules, CA, USA) at a wavelength of $450 \mathrm{~nm}$.

Reverse transcription-quantitative polymerase chain reaction (RT-qPCR). Total RNA was extracted from osteocytes using the RNA Easy Mini Extract kit (Sigma-Aldrich; Merck $\mathrm{KGaA}$ ) according to the manufacturer's protocol. RNA was reversed transcribed using a PrimeScript RT Master Mix kit (Takara Bio, Inc., Otsu, Japan). Subsequently, cDNA (10 $\mu \mathrm{g})$ was diluted $1 / 10$ with distilled water and $10 \mu \mathrm{l}$ was used for amplification. Specific primer sets for $\mathrm{C}-\mathrm{C}$ motif chemokine ligand $2(\mathrm{Ccl}) 2, \mathrm{Ccl} 5$ and intercellular adhesion molecule 1 (Icam1) were conserved in the laboratory (Table I). RT-qPCR was performed using a qPCR system (Invitrogen; Thermo Fisher Scientific, Inc., Waltham, MA, USA) with SYBR Green Master Mix (Invitrogen; Thermo Fisher Scientific, Inc.) according to the manufacturer's protocols. A total of 45 amplification cycles were performed, including $94^{\circ} \mathrm{C}$ for $30 \mathrm{sec}$, denaturation at $96^{\circ} \mathrm{C}$ for $5 \mathrm{sec}$, primer annealing at $64^{\circ} \mathrm{C}$ for $5 \mathrm{sec}$, touchdown to $56^{\circ} \mathrm{C}$ for $15 \mathrm{sec}$ and extension at $72^{\circ} \mathrm{C}$ for $10 \mathrm{sec}$. Relative mRNA expression levels were then determined using the $2^{-\Delta \Delta \mathrm{Cq}}$ method (24). The final results were presented as the fold of $\beta$-actin.

Osteocyte migration assay. Osteocytes were obtained from mice with fractures, and osteoblasts and osteoclasts were isolated from mice that had undergone fracture prior to treatment as described in a previous study (25). Osteoblasts and osteoclasts were suspended at a density of $1 \times 10^{6}$ in $100 \mu 1$ serum-free MEM for $12 \mathrm{~h}$. The cells were then seeded into the 
Table I. Primers used for reverse transcription-quantitative polymerase chain reaction.

\begin{tabular}{lll}
\hline Target gene & \multicolumn{1}{c}{ Forward primer } & \multicolumn{1}{c}{ Reverse primer } \\
\hline Ccl2 & 5'-AAGAAGCTGTAGTATTTGTCACCAAGCTCA-3' & 5'-CATCAGGTACGATCCAGGCT-3' \\
Ccl5 & 5'-GCAGCTGCATCCCTCACCGT-3' & 5'-GCAGCAGGGAGTGGTGTCCG-3' \\
Icam1 & 5'-GCTGTGCTTTGAGAACTGTG-3' & 5'-GTGAGGTCCTTGCCTACTTG-3' \\
$\beta$-actin & 5'-GTGGGCGCCCAGGCACCA-3' & 5'-CTCCTTAATGTCACGCACGATTT-3'
\end{tabular}

Ccl, C-C motif chemokine; Icam1, intercellular adhesion molecule 5.

upper chambers of a BD BioCoat Matrigel Invasion Chamber (BD Biosciences, Franklin Lakes, NJ, USA) and then incubated with $\mathrm{HGF}(2 \mathrm{mg} / \mathrm{ml})$ for $12 \mathrm{~h}$ at $37^{\circ} \mathrm{C}$. The migration assay was conducted according to the manufacturer's protocol.

Determination of $N F-\kappa B$ activity. Osteoblasts ( $1 \times 10^{6}$ cells) and osteoclasts $\left(1 \times 10^{6}\right.$ cells) were separately cultured in 6-well plates and incubated with either HGF $(2 \mathrm{mg} / \mathrm{ml})$ or PBS for $48 \mathrm{~h}$. The efficacy of HGF on NF- $\mathrm{B}$ activity was analyzed by determination of NF- $\kappa \mathrm{B}$-luciferase activity in cells. Briefly, cells were transfected with a $\mathrm{pNF}-\kappa \mathrm{B}-$ luciferase vector (Promega Corporation, Madison, WI, USA) for $48 \mathrm{~h}$ at $37^{\circ} \mathrm{C}$ using Lipofectamine ${ }^{\circledR} 2000$ (Invitrogen; Thermo Fisher Scientific, Inc.), according to manufacturer's instructions. Luciferase activity in the cells was determined $72 \mathrm{~h}$ post-transfection at $37^{\circ} \mathrm{C}$ by using the Dual-Luciferase Reporter Assay System (Promega Corporation) following the manufacturer's protocol. Relative luciferase activity was determined by analyzing the firefly luciferase activity and normalizing it with the Renilla luciferase activity.

Cells differentiation. Osteoblasts and osteoclasts were obtained from mice with fractures prior to treatment and then separately cultured with MEM medium supplemented with 10\% FBS. Cells were incubated with HGF $(2 \mathrm{mg} / \mathrm{ml})$ or the same volume of PBS $(2 \mathrm{mg} / \mathrm{ml})$ and then cultured for $72 \mathrm{~h}$ at $37^{\circ} \mathrm{C}$. Analysis of tartrateresistant acid phosphatase activity was used to determine osteoblast and osteoclast differentiation.

Western blotting. Osteocytes were obtained from mice with fractures and were homogenized in lysis buffer containing protease inhibitor to perform protein extraction (Sigma-Aldrich; Merck $\mathrm{KGaA}$ ), after which the cells were centrifuged at 6,000 $\mathrm{x} \mathrm{g}$ at $4^{\circ} \mathrm{C}$ for $10 \mathrm{~min}$. The supernatant was used for protein analysis. Protein concentration was determined using a BCA protein assay kit (Thermo Fisher Scientific, Inc.). Protein samples $(10 \mu \mathrm{g})$ were separated using $12.5 \%$ SDS-PAGE, as described in a previous study (23), and then transferred to polyvinylidene fluoride (PVDF) membranes (EMD Millipore, Billerica, MA, USA). For western blotting, following blocking with 5\% skimmed milk for $1 \mathrm{~h}$ at $37^{\circ} \mathrm{C}$, primary antibodies: VEGF (cat. no. ab32152; 1:1,000; Abcam, Cambridge, UK), BMP-2 receptor [(R); cat. no. ab38560; 1:1,000; Abcam)], macrophage colony-stimulating factor (M-CSF; cat. no. ab9693; 1:1,000; Abcam), receptor activator of $\mathrm{NF}-\kappa \mathrm{B}$ ligand (RANKL; cat. no. ab216484; 1:1,000; Abcam) and $\beta$-actin (cat. no. ab8226; 1:1,000; Abcam) were then incubated with PVDF membranes for $12 \mathrm{~h}$ at $4^{\circ} \mathrm{C}$. Subsequently, membranes were incubated with horseradish peroxidase (HRP)-conjugated goat anti-rabbit IgG mAb (cat. no. PV-6001; 1:5,000; OriGene Technologies, Inc., Beijing, China) for $24 \mathrm{~h}$ at $4^{\circ} \mathrm{C}$. Following this, protein bands were visualized using Western Bright Enhanced Chemiluminescent HRP Substrate (Advansta, Inc., Menlo Park, CA, USA).

Small interfering (si)RNA transfections. Osteocytes ( $1 \times 10^{6}$ cells) were cultured to $80 \%$ confluence and were transfected with siRNA sequences (100 pM; Invitrogen; Thermo Fisher Scientific, Inc.) that targeted BMP-2: si-BMP-2 sense, 5'-GUGCUAUCUCGAUGCUGUATT-3' and antisense, 5'-AAUACAGCAUCGAGAUAGCAC-3'; or scramble siRNA sense, 5'-GUGCUAUCUCGAUGCUGUA-3' and antisense, 5'-UACAGCAUUCGAGAUAGCAC-3'. Transfection was performed using Lipofectamine ${ }^{\circledR}$ RNAi MAX (Invitrogen; Thermo Fisher Scientific, Inc.) according to the manufacturer's protocol. Cells were cultured for $48 \mathrm{~h}$ at $37^{\circ} \mathrm{C}$ following transfection for further analysis.

Flow cytometry. On day 30, serum was obtained from experimental mice via centrifugation at $6,000 \mathrm{x}$ g for $15 \mathrm{~min}$ at $4^{\circ} \mathrm{C}$. Serum levels of lymphocytes, plasmacytes, neutrophils and monocytes in mice with fracture were analyzed by flow cytometry. All procedures were performed as described in a previous study (26). In addition, the ratios of apoptotic cells were determined using a Coulter EPICS XL Flow Cytometer (Beckman Coulter, Inc., Brea, CA, USA), and results were analyzed using Expo32-ADC v. 1.2B software (Beckman Coulter, Inc.).

ELISA. On day 30, to detect serum protein expression levels of inflammatory factors, mouse tumor necrosis factor (TNF)- $\alpha$ (cat. no. MTA00B; Bio-Rad Laboratories, Inc.), monocyte chemotactic protein (MCP)-1 (cat. no. CPCA00; Bio-Rad Laboratories, Inc.), interleukin (IL)-1 (cat. no. MLB00C; Bio-Rad Laboratories, Inc.) and IL-6 (cat. no. M6000B; Bio-Rad Laboratories, Inc.) ELISA kits were used. The experiments were conducted according to the manufacturer's protocols. Finally, absorbance of the samples was measured at $450 \mathrm{~nm}$ using an ELISA plate reader.

Histological analysis. To determine the therapeutic effects of HGF on a mouse model of fracture, the mice were sacrificed under pentobarbital anesthesia on day 30 and the bone tissues located in the fracture were separated and fixed in $10 \%$ formalin for $30 \mathrm{~min}$ at $37^{\circ} \mathrm{C}$. The tissues were subsequently decalcified 

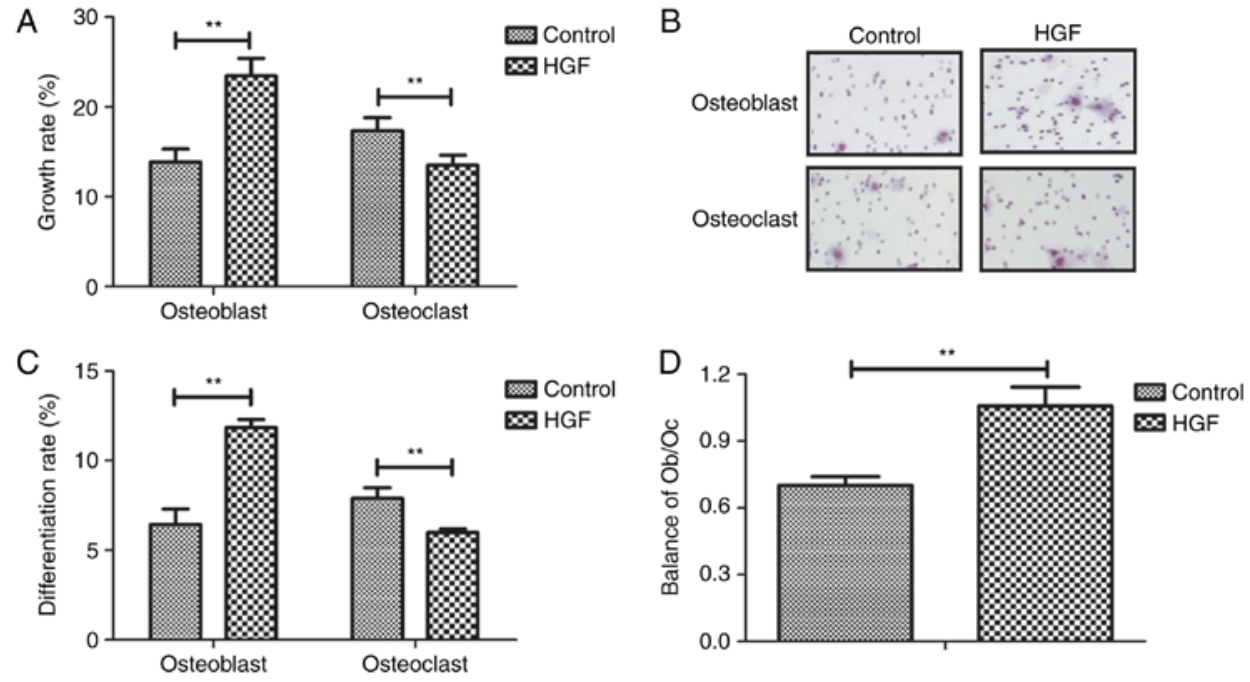

Figure 1. Effects of HGF on migration and differentiation of osteocytes in a mouse model of fracture. (A) Cell viability of osteoblasts was enhanced, whereas the viability of osteoclasts was inhibited in HGF-treated mice. (B) Migration of osteoblasts was enhanced, whereas the viability of osteoclasts was not affected in HGF-treated mice (magnification, x40). (C) Differentiation of osteoblasts was enhanced, whereas differentiation of osteoclasts was inhibited in HGF-treated mice. (D) $\mathrm{Ob} / \mathrm{Oc}$ balance in the fracture location. The results are expressed as the mean \pm standard deviation of three independent experiments. ${ }^{* *} \mathrm{P}<0.01 \mathrm{vs}$. the control group. HGF, hepatocyte growth factor; Ob/Oc, osteoblast/osteoclast.

and embedded in paraffin for $2 \mathrm{~h}$ at $37^{\circ} \mathrm{C}$. Paraffin-embedded bone tissues sections $(4 \mu \mathrm{g})$ from experimental mice were stained with hematoxylin and eosin for $2 \mathrm{~h}$ at $37^{\circ} \mathrm{C}$. Images were obtained using an inverted light microscope (Olympus Corporation, Tokyo, Japan).

Vascular density measurements and evaluation of bone resorption activity. Vascular density measurements and bone resorption activity were analyzed in mice following treatment with HGF, according to methods described in previous studies $(27,28)$.

Statistical analysis. All data are presented as the mean \pm standard deviation of triplicate experiments. All data were analyzed using SPSS Statistics 19.0 (IBM Corp., Armonk, NY, USA). Unpaired data were analyzed using Student's t-test $\mathrm{P}<0.05$ was considered to indicate a statistically significant difference.

\section{Results}

In vitro effects of HGF treatment on migration and differentiation of osteocytes from a mouse model of fracture. The present study analyzed the effects of HGF on migration and differentiation of osteoblasts and osteoclasts from osteocytes obtained from mice with fracture. As shown in Fig. 1A, HGF promoted cell viability of osteoblasts and inhibited the cell viability of osteoclasts. A migration assay indicated that HGF treatment slightly enhanced migration of osteoblasts; however, no effects were detected on osteoclast migration (Fig. 1B). In addition, the results demonstrated that HGF promoted differentiation of osteoblasts and inhibited differentiation of osteoclasts at the fracture location (Fig. 1C). Furthermore, the balance of osteoblasts and osteoclasts $(\mathrm{Ob} / \mathrm{Oc})$ was improved in the fracture location (Fig. 1D). Taken together, these results suggested that HGF treatment may regulate migration and differentiation of osteoblasts and osteoclasts in a mouse model of fracture.
Effects of HGF treatment on inflammatory factors and biochemical analysis in a mouse model of fracture. A previous study indicated that aggravation of inflammatory responses can inhibit bone regeneration (29). Therefore, the present study detected inflammatory factors and biochemical indicators in a mouse model of fracture following treatment with HGF. As shown in Fig. 2A-D, the expression levels of TNF- $\alpha$, MCP-1, IL-1 and IL-6 were downregulated in serum samples from HGF-treated experimental mice. Biochemical analysis indicated that the percentage of lymphocytes, plasmacytes, neutrophils and monocytes were also decreased in mice treated with HGF compared with PBS (Fig. 2E-H). These results suggested that HGF may be beneficial for the treatment of fractures in a mouse model via the downregulation of inflammatory responses.

Effects of HGF treatment on the expression levels of extracellular signaling molecules in a mouse model of fracture. After analyzing the alterations in inflammatory responses in a mouse model of fracture, the present study investigated the expression levels of extracellular signaling molecules. As presented in Fig. 3, the expression levels of VEGF, BMP-2R, RANKL and M-CSF were upregulated in the fracture location of HGF-treated mice. HGF-induced expression of extracellular signaling molecules may contribute to bone regeneration and bone healing in a mouse model of fracture. Taken together, these results suggested that HGF treatment increased the expression levels of extracellular signaling molecules in osteocytes in a mouse model of fracture.

Analysis of the mechanism underlying HGF-mediated $N F-\kappa B$ signaling in a mouse model of fracture. A previous study reported that NF- $\mathrm{kB}$ serves an essential role in bone regeneration via the regulation of numerous genes involved in cellular activity (30). Therefore, the present study analyzed the association between HGF and the NF- $\mathrm{KB}$ signaling pathway in a mouse model of fracture. As shown in Fig. 4A, treatment with HGF promoted NF- $\mathrm{\kappa B}$ activity in osteocytes. In addition, p65, 

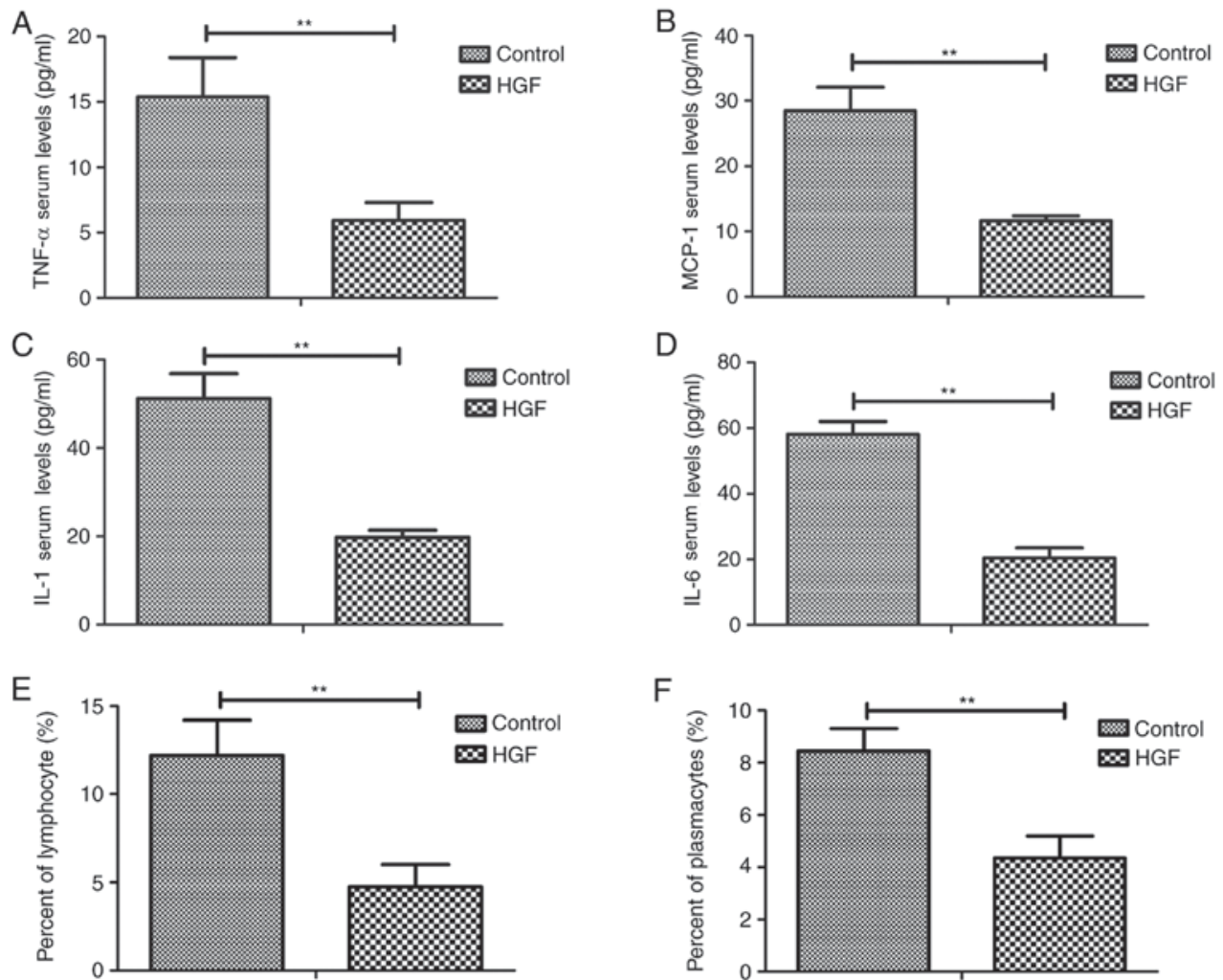

$\mathrm{F}$
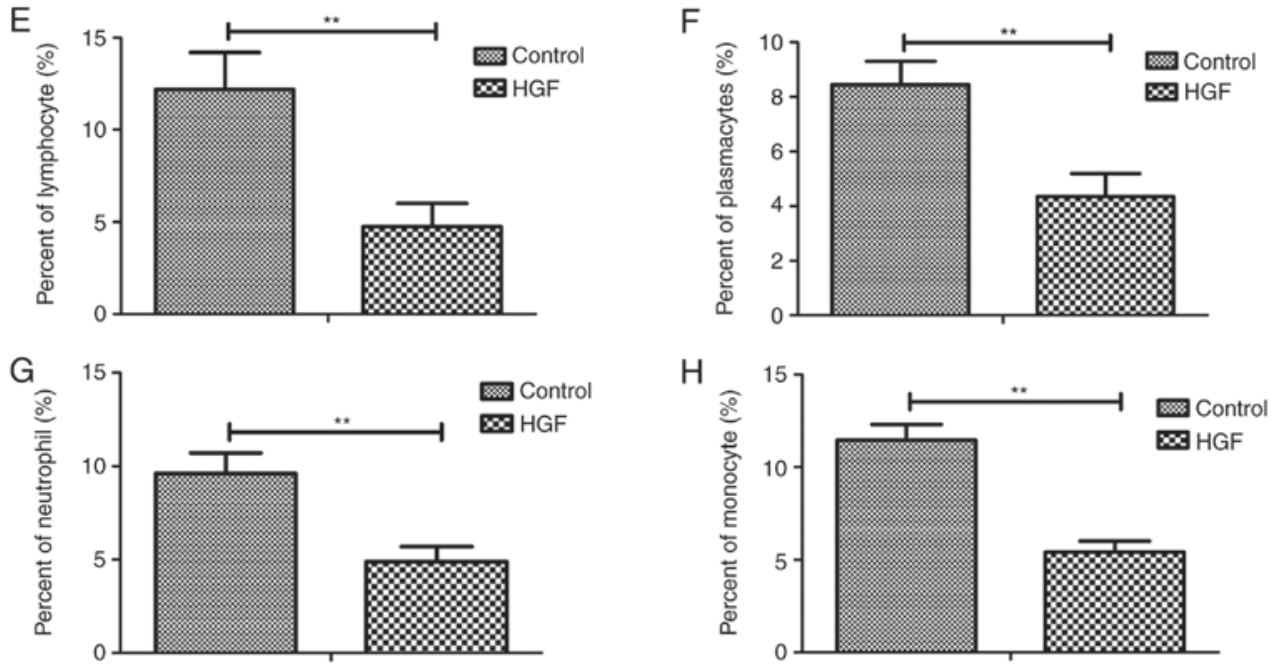

Figure 2. Analysis of HGF on inflammatory factors and biochemical analysis in a mouse model of fracture. Expression levels of (A) TNF- $\alpha$, (B) MCP-1, (C) IL-1 and (D) IL-6 in serum samples obtained from a mouse model of fracture. Percentage of (E) lymphocytes, (F) plasmacytes, (G) neutrophils and (H) monocytes was analyzed in a mouse model of fracture following treatment with HGF. The results are expressed as the mean \pm standard deviation of three independent experiments. ${ }^{* *} \mathrm{P}<0.01$ vs. the control group. HGF, hepatocyte growth factor; IL, interleukin; MCP-1, monocyte chemotactic protein-1; TNF- $\alpha$, tumor necrosis factor- $\alpha$.

A

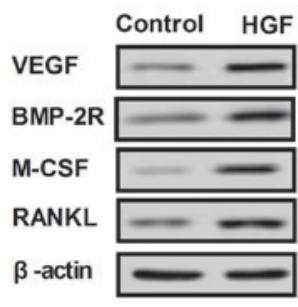

B

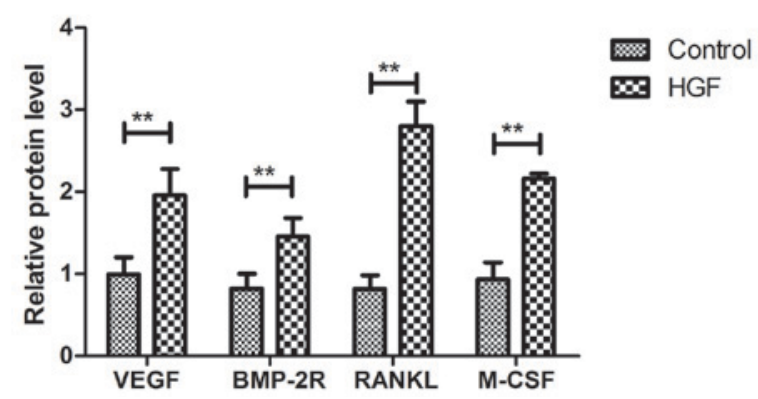

Figure 3. Alterations in the expression levels of extracellular signaling molecules in a mouse model of fracture following treatment with HGF. (A) Protein expression levels of VEGF, BMP-2R, RANKL and M-CSF in osteocytes from the fracture location of HGF-treated mice. (B) Semi-quantification of protein expression levels of VEGF, BMP-2R, RANKL and M-CSF in osteocytes from the fracture location of HGF-treated mice. The results are expressed as the mean \pm standard deviation of three independent experiments. ${ }^{* *} \mathrm{P}<0.01$ vs. the control group. BMP-2R, bone morphogenetic protein-2 receptor; HGF, hepatocyte growth factor; M-CSF, macrophage colony-stimulating factor; RANKL, receptor activator of nuclear factor- $\mathrm{kB}$ ligand; VEGF, vascular endothelial growth factor.

IKK- $\beta$ and IкB $\alpha$ expression levels were upregulated in osteocytes from experimental mice treated with HGF (Fig. 4B).
HGF treatment also increased the expression of the following anti-inflammatory genes, $\mathrm{Ccl} 2, \mathrm{Ccl} 5$ and Icam1, which are 

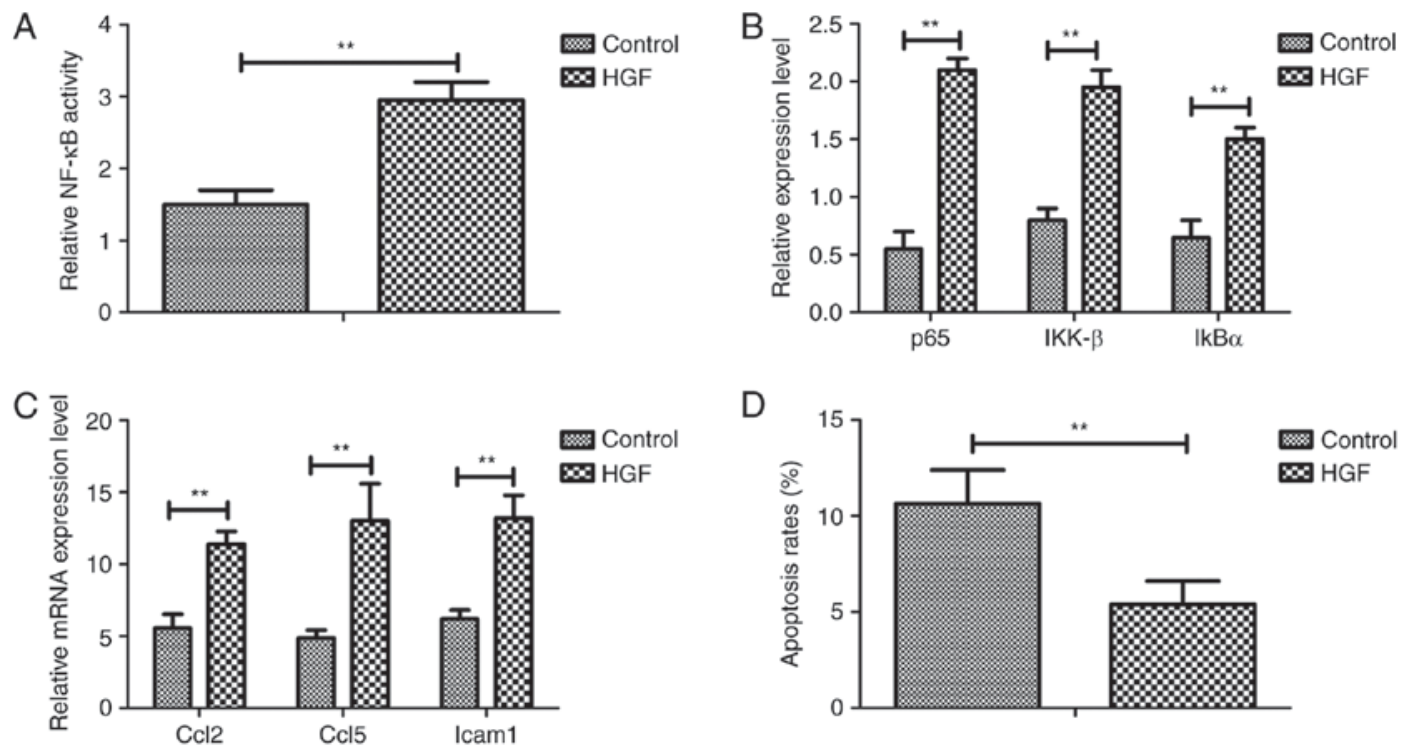

Figure 4. Mechanism underlying HGF-mediated NF-кB signaling in a mouse model of fracture. (A) NF- $\mathrm{kB}$ activity in osteocytes obtained from HGF-treated fractured mice. (B) Expression levels of p65, IKK- $\beta$ and I $\mathrm{KB} \alpha$ in osteocytes obtained from experimental mice treated with HGF. (C) Expression levels of Ccl2, Cc15 and Icam1 in osteocytes obtained from experimental mice treated with HGF. (D) Apoptosis of osteocytes obtained from experimental mice treated with HGF. The results are expressed as the mean \pm standard deviation of three independent experiments. ${ }^{* *} \mathrm{P}<0.01$ vs. the control group. BMP-2, bone morphogenetic protein-2;

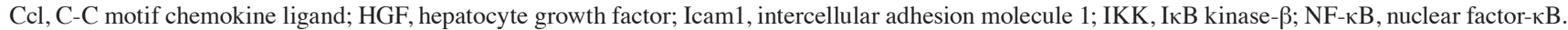

regulated by the $\mathrm{NF}-\kappa \mathrm{B}$ signaling pathway, as determined by RT-qPCR (Fig. 4C). Furthermore apoptosis of osteocytes was decreased in experimental mice treated with HGF (Fig. 4D). Taken together, these results indicated that HGF may regulate the physiological function of osteocytes via regulation of the $\mathrm{NF}-\kappa \mathrm{B}$ signaling pathway.

Analysis of HGF treatment on the expression levels of BMP-2 and revascularization-associated factors in a mouse model of fracture. The present study investigated the expression levels of BMP-2 and revascularization-associated factors in osteocytes from a mouse model of fracture. As shown in Fig. 5A, HGF upregulated BMP-2 expression in osteocytes from a mouse model of fracture. In addition, the expression levels of epidermal growth factor and FGF were increased in osteocytes from a mouse model of fracture (Fig. 5B). Inhibition of BMP-2 expression using siRNA (Si-BMP-2) decreased BMP-2 protein expression and inhibited $\mathrm{NF}-\kappa \mathrm{B}$ activity in osteocytes in vitro (Fig. $5 \mathrm{C}$ and $\mathrm{D}$ ). Furthermore, the results indicated that Si-BMP-2 suppressed the expression levels of p65, IKK- $\beta$ and $\mathrm{I} \kappa \mathrm{B} \alpha$ in osteocytes in vitro (Fig. $5 \mathrm{E}$ ). Taken together, these results suggested that HGF may enhance the $\mathrm{NF}-\kappa \mathrm{B}$ pathway via regulation of BMP-2 expression.

In vivo effects of HGF treatment on pathological alterations in a mouse model of fracture. The in vivo effects of HGF on a mouse model of fracture were also analyzed in the present study. As shown in Fig. 6A, HGF treatment increased body weight compared with in the PBS group. HGF also increased the bone resorption activity of mice (Fig. 6B). In addition, the vascular density of the HGF group was significantly increased compared with in the PBS group (Fig. 6C). The extent of bone regeneration and healing was also improved in HGF-treated fractured mice (Fig. 6D). These data suggested that HGF treatment may markedly improve bone resorption, neovascularization and bone regeneration, as determined by histological staining.

\section{Discussion}

Bone regeneration serves an essential role in fracture recovery, and is associated with bone resorption and bone-bonding ability (31,32). Previous studies have demonstrated that HGF is associated with cell regeneration and regulation of material-related bone formation $(33,34)$. Although previous studies have indicated that HGF is constitutively produced by donor-derived bone marrow cells and can promote regeneration of pancreatic $\beta$-cells $(35,36)$, the effects of $\mathrm{HGF}$ on bone regeneration have not been reported in previous studies. The present study investigated the effects, and potential molecular mechanisms, of HGF on bone regeneration in osteoblasts and osteoclasts in vitro and in fractured mice in vivo. The present study also studied the effects of HGF on inflammation in serum and apoptosis of osteocytes. The results indicated that HGF enhances the NF- $\mathrm{BB}$ pathway through the regulation of BMP-2 expression, which may markedly improve bone resorption, neovascularization and bone regeneration in a mouse model of fracture.

Theoretically, inflammatory cytokines are crucial regulatory factors in fracture progression that are mediated by various intracellular kinase signaling pathways, and regulate the local inflammatory response following acute tibial plateau fracture $(37,38)$. Although a previous study reported inflammatory/necrosis biomarkers in fractured femurs treated with proximal femoral nail antirotation (39), the molecular mechanism has not been clearly elaborated in previous reports. In addition, IL- 6 production modulated by HGF has been investigated in bone marrow-derived macrophages; the results revealed the role of HGF in inflammatory response-mediated diseases (40). Furthermore, overexpression of HGF in polycythemia vera attenuates the growth of clonal 
A
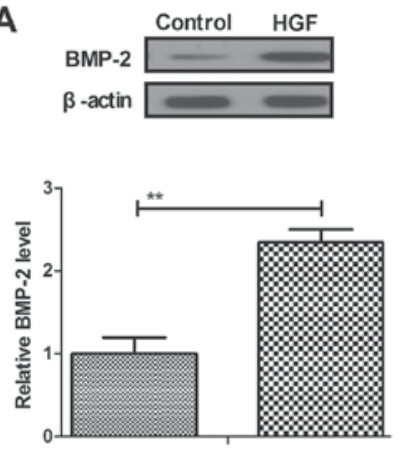

C
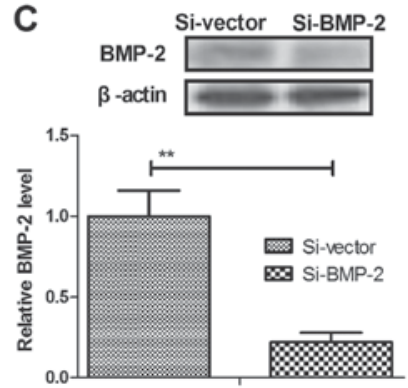

B

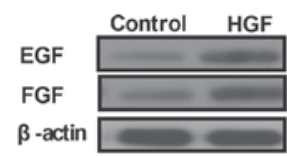

Control $\mathbf{B}$ HGF

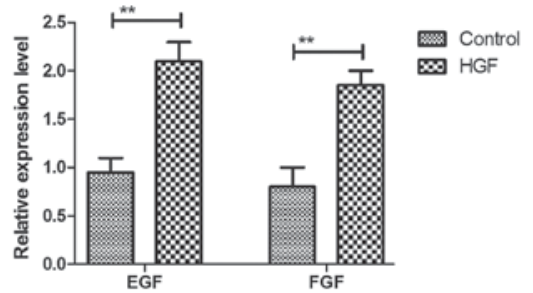

E
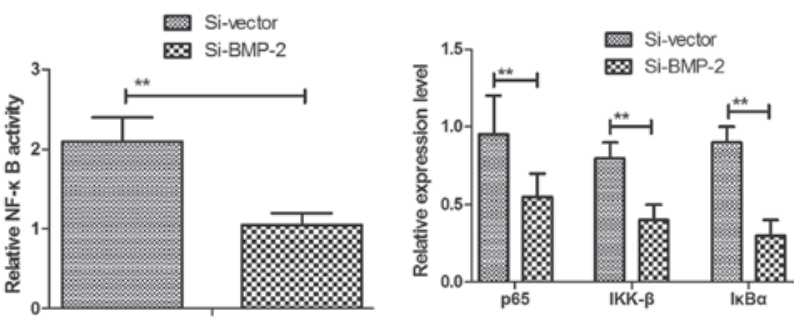

Figure 5. Effects of HGF on the expression levels of BMP-2 and revascularization-associated factors in a mouse model of fracture. (A) BMP-2 expression in osteocytes obtained from HGF-treated experimental mice. (B) Expression levels of EGF and FGF in osteocytes obtained from HGF-treated experimental mice. (C) Inhibition of BMP-2 decreased BMP-2 protein expression. (D) Effects Si-BMP-2 on NF- $\mathrm{kB}$ activity in osteocytes in vitro. (E) Effects of Si-BMP-2 on the expression levels of $\mathrm{p} 65$, IKK- $\beta$ and I $\kappa \mathrm{B} \alpha$ in osteocytes in vitro. The results are expressed as the mean \pm standard deviation of three independent experiments. ${ }^{* *} \mathrm{P}<0.01$ vs. the control group. EGF, epidermal growth factor; FGF, fibroblast growth factor; HGF, hepatocyte growth factor; IKK, IкB kinase- $\beta$; NF- $\kappa B$, nuclear factor- $\mathrm{kB}$; $\mathrm{Si}$, small interfering RNA.

A

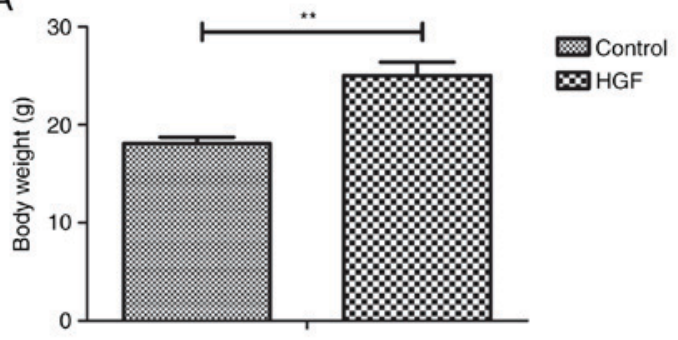

C

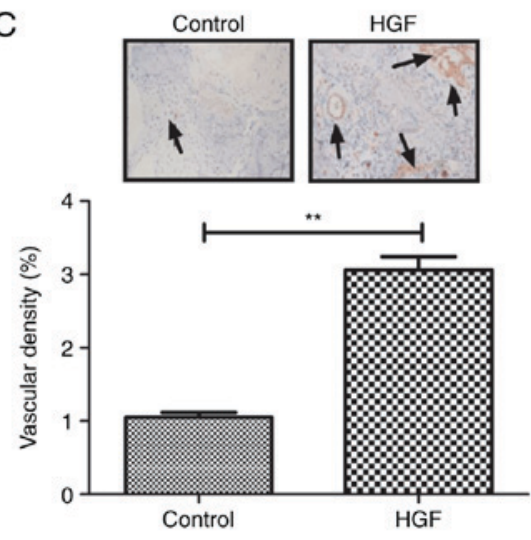

B

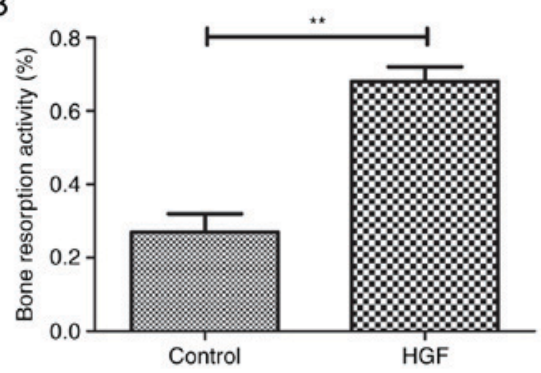

D

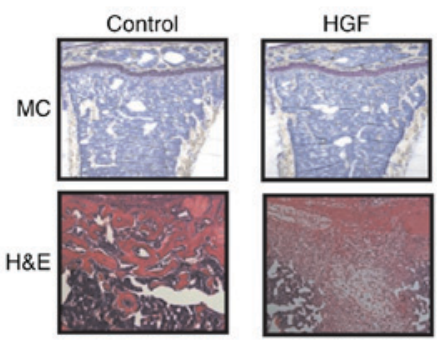

Figure 6. In vivo efficacy of HGF on pathological alterations in a mouse model of fracture. (A) Body weight of experimental mice following treatment with HGF. (B) Bone resorption activity of experimental mice following treatment with HGF. (C) Vascular density of experimental mice following treatment with HGF (magnification, $\mathrm{x} 40$ ). Arrows indicate vessels. (D) Bone regeneration and healing of experimental mice following treatment with HGF (magnification, $\mathrm{x} 40$ ). $\mathrm{MC}$, mass concentration. The results are expressed as the mean \pm standard deviation of three independent experiments. ${ }^{* *} \mathrm{P}<0.01$ vs. the control group. HGF, hepatocyte growth factor.

erythroblasts independently of $\mathrm{V} 617 \mathrm{~F}$ activating mutation of janus kinase 2 (41). Therefore, blocking inflammatory factors may interrupt the inflammatory process, thus breaking the vicious cycle of inflammation and promoting bone 
regeneration $(42,43)$. In the present study, HGF exerted beneficial effects on the treatment of a mouse model of fracture by downregulation of inflammatory responses. In addition, HGF upregulated BMP-2 expression in a mouse model of fracture.

BMPs are members of the transforming growth factor- $\beta$ superfamily, which regulate cellular metabolism, signaling pathways and numerous cell functions, including cell proliferation, migration, apoptosis, differentiation and adhesion $(44,45)$. In recent years, reports have suggested that BMP-2 may be used to reconstruct segmental mandibular defects and effectively repair ischemic damage by inducing angiogenesis and osteogenesis, and by decreasing osteoclast bone resorption activity $(46,47)$. In the present study, the association between HGF and BMP-2 was analyzed in a mouse model of fracture. Previous studies have reported that HGF contributes to fracture repair by upregulating the expression of BMPRs $(48,49)$. It has also been suggested that BMP-2 promotes bone formation and osteoblastic differentiation by endochondral ossification $(50,51)$. In addition, downregulation of BMPR expression is exhibited in mesenchymal cells from the joints of patients with rheumatoid arthritis (52). Furthermore, BMP-2 been clinically applied for spinal fusion procedures and it has been reported effectively regulate joint inflammation and damage $(53,54)$. The results of the present study confirmed that HGF is an efficient drug for promotion of bone regeneration via BMP-2-induced NF- $\kappa \mathrm{B}$ signaling.

A previous study indicated that the $\mathrm{NF}-\kappa \mathrm{B}$ signaling pathway has an essential role in bone regeneration and neovascularization via regulating the expression of VEGF, BMP-2, RANKL and $\mathrm{M}-\mathrm{CSF}$ expression in fracture progression (55). Notably, HGF has been reported to preferentially stimulate NF- $\kappa \mathrm{B}$ signaling, in order to protect renal proximal tubular epithelial cells against inflammation (43). In addition, BMP-2 exerts regulatory effects on apoptosis of chondrocytes, which serves a crucial role in the survival of chondrocytes (56). Furthermore, the NF- $\mathrm{B}$ signaling pathway may stimulate BMP-2 gene expression in growth plate chondrocytes in vivo and in a chondrocyte cell line in vitro (57). In the present study, HGF was revealed to stimulate BMP-2-mediated NF- $\kappa$ B signaling, which may be responsible for the downregulation of the expression of TNF- $\alpha$, IL- 6 and IL-1 inflammatory factors. Outcomes have indicated that HGF-mediated NF- $\kappa$ B signaling may be attributed to BMP-2 upregulation, which may promote bone regeneration.

In conclusion, the results of the present study suggest that further investigation is required to determine the overall role of HGF in entire joint cytokine homeostasis, neovascularization and bone regeneration. The present findings indicated that $\mathrm{HGF}$ is beneficial for bone regeneration via increased expression of BMP-2, which leads to neovascularization and bone regeneration through regulation of the $\mathrm{NF}-\kappa \mathrm{B}$ signaling pathway. These preclinical data provided information that may be useful for the future treatment of patients with fractures.

\section{References}

1. Furuya H, Tabata $\mathrm{Y}$ and Kaneko K: Bone regeneration for murine femur fracture by gelatin hydrogels incorporating basic fibroblast growth factor with different release profiles. Tissue Eng Part A 20: 1531-1541, 2014

2. Wang X, Wang Y, Gou W, Lu Q, Peng J and Lu S: Role of mesenchymal stem cells in bone regeneration and fracture repair: A review. Int Orthop 37: 2491-2498, 2013.
3. Thorimbert V, König D, Marro J, Ruggiero F and Jaźwińska A: Bone morphogenetic protein signaling promotes morphogenesis of blood vessels, wound epidermis, and actinotrichia during fin regeneration in zebrafish. FASEB J 29: 4299-4312, 2015.

4. Perez RA, Kim JH, Buitrago JO, Wall IB and Kim HW: Novel therapeutic core-shell hydrogel scaffolds with sequential delivery of cobalt and bone morphogenetic protein-2 for synergistic bone regeneration. Acta Biomater 23: 295-308, 2015.

5. Rozen N, Lewinson D, Bick T, Meretyk S and Soudry M: Role of bone regeneration and turnover modulators in control of fracture. Crit Rev Eukaryot Gene Expr 17: 197-213, 2007.

6. Hutchison C, Pilote M and Roy S: The axolotl limb: A model for bone development, regeneration and fracture healing. Bone 40: 45-56, 2007.

7. Hankenson KD, Gagne K and Shaughnessy M: Extracellular signaling molecules to promote fracture healing and bone regeneration. Adv Drug Deliv Rev 94: 3-12, 2015.

8. Suzuki A, Uemura T and Nakamura H: Control of bone remodeling by nervous system. Neural involvement in fracture healing and bone regeneration. Clin Calcium 20: 1820-1827, 2010 (In Japanese).

9. Tewari D, Khan MP, Sagar N, China SP, Singh AK, Kheruka SC, Barai S, Tewari MC, Nagar GK, Vishwakarma AL, et al: Ovariectomized rats with established osteopenia have diminished mesenchymal stem cells in the bone marrow and impaired homing, osteoinduction and bone regeneration at the fracture site. Stem Cell Rev 11: 309-321, 2015.

10. Ramezani A, Nägga K, Hansson O, Lönn J, Sjöwall J, Katoozian F, Mansouri S and Nayeri F: Hepatocyte growth factor in cerebrospinal fluid differentiates community-acquired or nosocomial septic meningitis from other causes of pleocytosis. Fluids Barriers CNS 12: 22, 2015.

11. Faletto DL, Kaplan DR, Halverson DO, Rosen EM and Vande Woude GF: Signal transduction in c-met mediated motogenesis. EXS 65: 107-130, 1993.

12. Baum E, Pawlaczyk K, Mackowiak B, Maćkowiak B, Sosinska P, Matecka M, Kolodziejczak B, Musielak M and Breborowicz A: Levels of hepatocyte growth factor in serum correlate with quality of life in hemodialysis patients. Int J Clin Exp Pathol 8: 13477-13482, 2015.

13. Mizuno S and Nakamura T: Molecular basis for HGF-mediated regression of renal fibrosis. Nihon Rinsho 64 (Suppl 2): S312-S321, 2006.

14. Zhang SH, Wen KM, Wu W, Li WY and Zhao JN: Efficacy of HGF carried by ultrasound microbubble-cationic nano-liposomes complex for treating hepatic fibrosis in a bile duct ligation rat model, and its relationship with the diffusion-weighted MRI parameters. Clin Res Hepatol Gastroenterol 37: 602-607, 2013.

15. Singh K, Massel DH, Mayo BC, Bohl DD, Long WW and Modi KD: Bone morphogenetic proteins in lumbar arthrodesis: What is all the debate about? Commentary on an article by Daniel C. Beachler, PhD, MHS, et al: 'Bone morphogenetic protein use and cancer risk among patients undergoing lumbar arthrodesis: A case-cohort study using the SEER-medicare database'. J Bone Joint Surg Am 98: e57, 2016.

16. Yamamoto M, Hokugo A, Takahashi Y, Nakano T, Hiraoka M and Tabata Y: Combination of BMP-2-releasing gelatin $/ \beta-\mathrm{TCP}$ sponges with autologous bone marrow for bone regeneration of X-ray-irradiated rabbit ulnar defects. Biomaterials 56: 18-25, 2015.

17. Grcevic D, Jajic Z, Kovacic N, Lukic IK, Velagic V, Grubisic F, Ivcevic S and Marusic A: Peripheral blood expression profiles of bone morphogenetic proteins, tumor necrosis factor-superfamily molecules, and transcription factor Runx 2 could be used as markers of the form of arthritis, disease activity, and therapeutic responsiveness. J Rheumatol 37: 246-256, 2010.

18. Lories RJ and Luyten FP: Bone morphogenetic proteins in destructive and remodeling arthritis. Arthritis Res Ther 9: 207, 2007.

19. Postigo J, Iglesias M, Álvarez P, Jesús Augustin J, Buelta L, Merino J and Merino R: Bone morphogenetic protein and activin membrane-bound inhibitor, a transforming growth factor $\beta$ rheostat that controls murine treg cell/Th17 cell differentiation and the development of autoimmune arthritis by reducing interleukin-2 signaling. Arthritis Rheumatol 68: 1551-1562, 2016.

20. Brescia AC, Simonds MM, McCahan SM, Fawcett PT and Rose CD: The role of transforming growth factor $\beta$ signaling in fibroblast-like synoviocytes from patients with oligoarticular juvenile idiopathic arthritis: Dysregulation of transforming growth factor $\beta$ signaling, including overexpression of bone morphogenetic protein 4 , may lead to a chondrocyte phenotype and may contribute to bony hypertrophy. Arthritis Rheumatol 66: 1352-1362, 2014. 
21. Holstein JH, Schmalenbach J, Herrmann M, Ölkü I, Garcia P, Histing T, Herrmann W, Menger MD, Pohlemann T and Claes L: Excess dietary methionine does not affect fracture healing in mice. Med Sci Monit 18: BR469-BR474, 2012.

22. Wan Q, Schoenmaker T, Jansen ID, Bian Z, de Vries TJ and Everts V: Osteoblasts of calvaria induce higher numbers of osteoclasts than osteoblasts from long bone. Bone 86: 10-21, 2016.

23. Aino M, Nishida E, Fujieda Y, et al: Isolation and characterization of the human immature osteoblast culture system from the alveolar bones of aged donors for bone regeneration therapy. Expert Opin Biol Ther 14: 1731-1744, 2014.

24. Livak KJ and Schmittgen TD: Analysis of relative gene expression data using real-time quantitative PCR and the 2(-Delta Delta C(T)) method. Methods 25: 402-408, 2001.

25. Wai-Hoe L, Wing-Seng L, Ismail Z and Lay-Harn G: SDS-PAGE-based quantitative assay for screening of kidney stone disease. Biol Proced Online 11: 145-160, 2009.

26. Bajnok A, Kaposi A, Kovács L, Vásárhelyi B, Balog A and Toldi G: Analysis by flow cytometry of calcium influx kinetics in peripheral lymphocytes of patients with rheumatoid arthritis. Cytometry A 83: 287-293, 2013.

27. Kinsella S, Murphy K, Breen M, O'Neill S, McLaughlin P, Coyle J, Bogue C, O'Neill F, Moore N, McGarrigle A, et al: Comparison of single CT scan assessment of bone mineral density, vascular calcification and fat mass with standard clinical measurements in renal transplant subjects: The ABC HeART study. BMC Nephrol 16: 188, 2015.

28. Morimoto Y, Hoshino H, Sakurai T, Terakawa S and Nagano A: Quantitative evaluation of bone resorption activity of osteoclast-like cells by measuring calcium phosphate resorbing area using incubator-facilitated and video-enhanced microscopy. Microsc Res Tech 72: 317-322, 2009.

29. Thomas MV and Puleo DA: Infection, inflammation, and bone regeneration: A paradoxical relationship. J Dent Res 90: 1052-1061, 2011

30. Mallavia B, Recio C, Oguiza A, Ortiz-Muñoz G, Lazaro I, Lopez-Parra V, Lopez-Franco O, Schindler S, Depping R, Egido $\mathrm{J}$ and Gomez-Guerrero C: Peptide inhibitor of NF- $\kappa \mathrm{B}$ translocation ameliorates experimental atherosclerosis. Am J Pathol 182: 1910-1921, 2013.

31. Xinluan W, Yuxiao L, Helena NH, Zhijun Y and Ling Q Systemic drug delivery systems for bone tissue regeneration-a mini review. Curr Pharm Des 21: 1575-1583, 2015.

32. Gibbs DM, Black CR, Dawson JI and Oreffo RO: A review of hydrogel use in fracture healing and bone regeneration. J Tissue Eng Regen Med 10: 187-198, 2016.

33. Tomson PL, Lumley PJ, Alexander MY, Smith AJ and Cooper PR: Hepatocyte growth factor is sequestered in dentine matrix and promotes regeneration-associated events in dental pulp cells. Cytokine 61: 622-629, 2013.

34. Madonna R, Cevik C, Nasser M and De Caterina R: Hepatocyte growth factor: Molecular biomarker and player in cardioprotection and cardiovascular regeneration. Thromb Haemost 107 656-661, 2012

35. Jin SZ, Meng XW, Sun X, Han MZ, Liu BR, Wang XH and Pei FH: Hepatocyte growth factor promotes liver regeneration induced by transfusion of bone marrow mononuclear cells in a murine acute liver failure model. J Hepatobiliary Pancreat Sci 18: 397-405, 2011

36. Izumida $Y$, Aoki T, Yasuda D, Koizumi T, Suganuma $C$, Saito K, Murai N, Shimizu Y, Hayashi K, Odaira M, et al: Hepatocyte growth factor is constitutively produced by donor-derived bone marrow cells and promotes regeneration of pancreatic beta-cells. Biochem Biophys Res Commun 333: 273-282, 2005

37. Harvey EJ: Knee trauma and posttraumatic osteoarthritis-more science needed: Commentary on an article by Justin $\mathbf{M}$ Haller, MD, et al: 'Inflammatory cytokine response following acute tibial plateau fracture'. J Bone Joint Surg Am 97: e33, 2015

38. Haller JM, McFadden M, Kubiak EN and Higgins TF: Inflammatory cytokine response following acute tibial plateau fracture. J Bone Joint Surg Am 97: 478-483, 2015.

39. Marino M, Palmieri G, Peruzzi M, Scuderi F and Bartoccioni E: A study of inflammatory/necrosis biomarkers in the fracture of the femur treated with proximal femoral nail antirotation. Mediators Inflamm 2015: 189864, 2015.

40. Coudriet GM, He J, Trucco M, Mars WM and Piganelli JD: Hepatocyte growth factor modulates interleukin-6 production in bone marrow derived macrophages: Implications for inflammatory mediated diseases. PLoS One 5: e15384, 2010.
41. Boissinot M, Cleyrat C, Vilaine M, Jacques Y, Corre I and Hermouet S: Anti-inflammatory cytokines hepatocyte growth factor and interleukin-11 are over-expressed in Polycythemia vera and contribute to the growth of clonal erythroblasts independently of JAK2V617F. Oncogene 30: 990-1001, 2011.

42. Katz MS, Thatch KA and Schwartz MZ: Hepatocyte growth factor and omega-3-enriched feeds have a synergistic effect on mucosal mass in an animal model of inflammatory bowel disease. J Pediatr Surg 47: 194-198, 2012.

43. da Silva CG, Maccariello ER, Wilson SW, Putheti P, Daniel S, Damrauer SM, Peterson CR, Siracuse JJ, Kaczmarek E and Ferran C: Hepatocyte growth factor preferentially activates the anti-inflammatory arm of NF- $\mathrm{BB}$ signaling to induce A20 and protect renal proximal tubular epithelial cells from inflammation. J Cell Physiol 227: 1382-1390, 2012.

44. Sasikumar KP, Elavarasu S and Gadagi JS: The application of bone morphogenetic proteins to periodontal and peri-implant tissue regeneration: A literature review. J Pharm Bioallied Sci 4 (Suppl 2): S427-S430, 2012

45. Bragdon B, Moseychuk O, Saldanha S, King D, Julian J and Nohe A: Bone morphogenetic proteins: A critical review. Cell Signal 23: 609-620, 2011 .

46. Hustedt JW and Blizzard DJ: The controversy surrounding bone morphogenetic proteins in the spine: A review of current research. Yale J Biol Med 87: 549-561, 2014.

47. Dagostino PR, Whitmore RG, Smith GA, Maltenfort MG and Ratliff JK: Impact of bone morphogenetic proteins on frequency of revision surgery, use of autograft bone, and total hospital charges in surgery for lumbar degenerative disease: Review of the Nationwide inpatient sample from 2002 to 2008. Spine J 14: 20-30, 2014.

48. Imai $Y$, Terai H, Nomura-Furuwatari $C$, Mizuno S, Matsumoto K, Nakamura T and Takaoka K: Hepatocyte growth factor contributes to fracture repair by upregulating the expression of BMP receptors. J Bone Miner Res 20: 1723-1730, 2005.

49. Ye L, Lewis-Russell JM, Davies G, Sanders AJ, Kynaston H and Jiang WG: Hepatocyte growth factor up-regulates the expression of the bone morphogenetic protein (BMP) receptors, BMPR-IB and BMPR-II, in human prostate cancer cells. Int $\mathrm{J}$ Oncol 30 521-529, 2007.

50. Okubo Y, Bessho K, Fujimura K, Kusumoto K, Ogawa Y and Iizuka T: Osteogenesis by recombinant human bone morphogenetic protein-2 at skeletal sites. Clin Orthop Relat Res: 295-301, 2000.

51. Ozeç Y, Oztürk M, Kýlýç E, Yeler H, Göze F and Gümüs C: Effect of recombinant human bone morphogenetic protein-2 on mandibular distraction osteogenesis. J Craniofac Surg 17: 80-83, 2006.

52. Marinova-Mutafchieva L, Taylor P, Funa K, Maini RN and Zvaifler NJ: Mesenchymal cells expressing bone morphogenetic protein receptors are present in the rheumatoid arthritis joint. Arthritis Rheum 43: 2046-2055, 2000.

53. Issa JP, do Nascimento C, Lamano T, Iyomasa MM, Sebald W and de Albuquerque RF Jr: Effect of recombinant human bone morphogenetic protein- 2 on bone formation in the acute distraction osteogenesis of rat mandibles. Clin Oral Implants Res 20: 1286-1292, 2009.

54. Yonezawa H, Harada K, Ikebe T, Shinohara M and Enomoto S: Effect of recombinant human bone morphogenetic protein-2 (rhBMP-2) on bone consolidation on distraction osteogenesis: A preliminary study in rabbit mandibles. J Craniomaxillofac Surg 34: 270-276, 2006.

55. Wang J, Wang K, Shi Z and Zhang M: Osteoprotegerin mRNA/receptor activator of NF-kappaB ligand mRNA expressions in bone tissues of glucocorticoid-induced osteonecrosis of the femoral head. Zhongguo Xiu Fu Chong Jian Wai Ke Za Zhi 22: 1161-1164, 2008 (In Chinese).

56. Sugimori K, Matsui K, Motomura H, Tokoro T, Wang J, Higa S, Kimura T and Kitajima I: BMP-2 prevents apoptosis of the N1511 chondrocytic cell line through PI3K/Akt-mediated NF-kappaB activation. J Bone Miner Metab 23: 411-419, 2005.

57. Feng JQ, Xing L, Zhang JH, Zhao M, Horn D, Chan J, Boyce BF, Harris SE, Mundy GR and Chen D: NF-kappaB specifically activates BMP-2 gene expression in growth plate chondrocytes in vivo and in a chondrocyte cell line in vitro. J Biol Chem 278: 29130-29135, 2003. 